\title{
Enzymatic analysis of yeast cell wall-resident GAPDH and its secretion
}

2

3

4

$7{ }^{1}$ Biology Department, Brooklyn College of the City University of New York, Brooklyn, 8 New York, 11210 USA

92 The Graduate Center of the City University of New York, New York, New York, 10016 10 USA

11

12

13 Keywords: cell wall, disulfide reduction, membrane integrity, enzyme assay, spheroplast

14 Running Title: Cell wall GAPDH

15

$16{ }^{*}$ Corresponding Author

17 Peter Lipke

18 Biology Department, Brooklyn College

192900 Bedford Ave.

20 Brooklyn, NY 11210 USA

21 plipke@brooklyn.cuny.edu

$22 \quad 718-951-5000$ ext 1949 


\section{Abstract}

In yeast, many proteins are found both in the cytoplasmic and extracellular compartments, and consequently it can be difficult to distinguish non-conventional secretion from cellular leakage. We therefore monitored extracellular glyceraldehyde-3phosphate dehydrogenase (GAPDH) activity of intact cells as a specific marker for nonconventional secretion. Extracellular GAPDH activity was proportional to the number of cells assayed, increased with incubation time, and was dependent on added substrates. Preincubation of intact cells with $100 \mu \mathrm{M}$ dithiothreitol increased the reaction rate, consistent with increased access of the enzyme after reduction of cell wall disulfide crosslinks. Such treatment did not increase cell permeability to propidium iodide, in contrast to effects of higher concentrations of reducing agents. An amine-specific membrane-impermeant biotinylation reagent specifically inactivated extracellular GAPDH. The enzyme was secreted again after a 30-60-minute lag following the inactivation, and there was no concomitant increase in propidium iodide staining. There were about $4 \times 10^{4}$ active GAPDH molecules per cell at steady state, and secretion studies showed replenishment to that level one hour after inactivation. These results establish conditions for specific quantitative assays of cell wall proteins in the absence of cytoplasmic leakage and for subsequent quantification of secretion rates in intact cells. 
44 Eukaryotic cells secrete many proteins, including many proteins that do not follow the classical secretion pathway. Among these, the glycolytic enzyme glyceraldehyde-3-phosphate dehydrogenase (GAPDH) is unexpectedly found in the walls of yeasts and other fungi, and in extracellular space in mammalian cell cultures. It is difficult to quantify extracellular GAPDH, because leakage of just a little of the very large amount of cytoplasmic enzyme can invalidate the determinations. We used enzymatic assays of intact cells, while also maintaining membrane integrity. The results lead to estimates of the amount of extracellular enzyme, and its rate of

51 secretion to the wall in intact cells. Therefore, enzyme assays under controlled conditions can

52 be used to investigate non-conventional secretion more generally.

Introduction

The glycolytic enzyme glyceraldehyde-3-phosphate dehydrogenase (GAPDH) is unexpectedly found in the walls of Saccharomyces cerevisiae, Candida albicans, and

57 Paracoccidiodides brasiliensis (1-8). The enzyme is also secreted from mammalian cells in

58 culture (9-11). Like many glycolytic proteins, GAPDH is a moonlighting protein with additional

59 roles both within the cell $(12,13)$ and externally; in $C$. albicans cell wall GAPDH binds

60 fibronectin (14), and in S. cerevisiae its secreted form is cleaved into antimicrobial peptides (15,

61 16). Recent cell wall proteomics work has shown cell wall localization of GAPDH in C. albicans

62 and non-albicans species $(17,18)$. The protein is present in walls, and in many cases its concentration is increased after growth in media that mimic mammalian conditions. Thus GAPDH is a common wall marker in pathogenic yeasts and may be important in host-pathogen interactions. 
remain elusive. Mass spectrometry of protease-treated cell walls or of intact cells generates peptides from enolase, alcohol dehydrogenase, and GAPDH, as well as cytosolic chaperones such as Ssa1, and Ssa2 in both $S$. cerevisiae $(4)$ and $C$. albicans $(6,19)$. Thus, GAPDH is prototypical of many unconventionally secreted proteins (20), as defined by their presence in the extracellular compartment despite their lack of canonical secretion signal peptides.

S. cerevisiae can be engineered to display and anchor enzymes on the cell wall for biofuel production (21), bioremediation (22), or library screening (23). The cell walls consist of polysaccharides including $\beta 1,3$ glucans, $\beta 1,6$ glucans, and chitin, and a large number of proteins. These cell wall resident proteins crosslink the saccharides, act as adhesins, regulate metabolic activities, and perform other functions (24-26). Most of these proteins are secreted through the conventional secretion-signal-dependent pathway that processes the proteins through the ER and Golgi $(27,28)$. This pathway was famously elucidated through a combination of enzymology and genetic screens (28). Temperature sensitive S. cerevisiae secretory mutants were generated, and at non-permissive temperatures they showed defects in invertase and acid phosphatase secretion (29).

Yeast have also been used to study unconventional protein secretion of proteins which lack a signal peptide. S. cerevisiae expressing the mammalian protein Galectin-1 could secrete it without using its classical secretory system (30), much as the protein behaves in mammalian cells (31). Mutational studies in in S. cerevisiae identified an Acb1 secretory mechanism that requires autophagy, Golgi proteins, as well as endosome components $(32,33)$. The chitinase Cts1 from Ustilago maydis was used to study a novel form of unconventional protein secretion at budding sites (34). Yeast species are also used to characterize unconventional secretion secretion into extracellular vesicles $(20,35-37)$. Thus, yeast is now a classic model for study of secretory pathways in general. 
We are interested in studying unconventional secretion of proteins such as GAPDH

93 using an enzymology approach. However, GAPDH is abundant in cytosol, there is a critical

94 need to obtain cell wall extracts while avoiding cytosolic contamination. We therefore describe

95 procedures for quantitative assay of extracellular GAPDH, and techniques for its extraction

96 without contamination by cytosolic enzyme.

97 


\section{Results}

\section{GAPDH activity in the wall of intact S. cerevisiae}

We verified that GAPDH is enzymatically active in the wall of $S$. cerevisiae strain BY4743 by resuspending cells in $1 \mathrm{mM}$ NAD, 1 mM glyceraldehyde-3-phosphate, $100 \mu \mathrm{M}$ DTT, and triethanolamine phosphate (TEA) buffer $(\mathrm{pH} 8.6)$ in a $200 \mu \mathrm{L}$ reaction, using methods similar to that of Delgado et al (1). However, we extended their results by establishing the wallassociated activity on a per cell basis. We suspended different concentrations of $S$. cerevisiae in GAPDH substrates for 30 minutes then measured NADH production. Yeast cells were pelleted by centrifugation, and NADH was measured as $\mathrm{A}_{340 .} \mathrm{NADH}$ production was linear with cell number up to $1.5 \times 10^{6}$ per $200 \mu \mathrm{L}$ reaction (Fig. 1A). Therefore, subsequent experiments
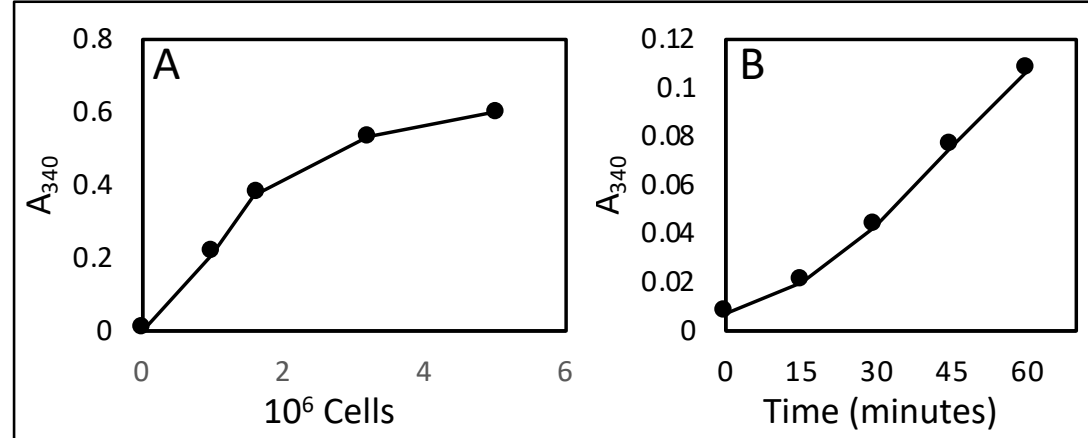

Fig. 1. Enzymological characteristics of cell wall GAPDH assays. A) Dependence on cell number in a 30 min assay. B) Time course of the assay with $5 \times 10^{5}$ cells.

used a maximum of $1 \times 10^{6}$ cells in $200 \mathrm{uL}$, with a majority of trials using $5 \times 10^{5}$ cells. The reaction rate was linear between 30 and 60 minutes, but showed a lag before that time (Fig. 1B). The origin of the lag is addressed in the next section.

Other enzymological controls were as expected. There was no measurable activity in the absence of added NAD+ or glyceraldehyde-3-phosphate. This data shows that all assayed $\mathrm{NAD}+$ reductase activity was due to GAPDH, and there was no endogenous activity due to leakage of either substrate from the cytoplasm. The absorbance spectrum of the product matched $\mathrm{NADH}$, and the optimum reaction $\mathrm{pH}$ was 8.6, consistent with known GAPDH properties (38) This $\mathrm{pH}$ value suggests that cell surface GAPDH is not enzymatically active during yeast growth, which normally occurs under acidic conditions. 


\section{Cell surface GAPDH activity increases during assays}

In 60- and 90-minute assays, the rate of NADH production increased (Fig. 2). This increase emphasized the lag time apparent in Fig. 1B. This result suggested that either GAPDH was accumulating at the surface, or that more extracellular GAPDH became active during the extended incubation in assay buffer.

GAPDH can be partially oxidized in vivo, reducing its activity by $10 \%$, so standard assays contain dithiothreitol (DTT) to keep the enzyme reduced (39). Our assay buffer contained $100 \mu \mathrm{M}$ DTT, as in Delgado et al. $(1,2)$. However, DTT can also break disulfide bonds in the wall and increase cell wall porosity $(5,40)$, exposing more enzyme to substrates (41-43). To test whether DTT was facilitating increased cell wall GAPDH activity, we assayed activity in the presence or absence of $100 \mu \mathrm{M}$ DTT. The rate of NADH production was greater in the presence of DTT than without it, and the rate of increase was maximum between 30 and 60 min of incubation (Fig. 2). This finding was confirmed in a preincubation experiment. Cells were pre-incubated in assay buffer in the absence of substrate, and in the presence or absence of DTT, $100 \mu \mathrm{M}$. Substrates were then added and enzyme activity monitored in standard $30 \mathrm{~min}$ assays. Preincubation in DTT increased GAPDH activity at the cell surface in a subsequent

GAPDH assay. Therefore, DTT

treatment either increased the fraction

of surface GAPDH that was

enzymatically active, or promoted surface accumulation of the enzyme, or both.

\section{GAPDH on the surface can be} attenuated with a membraneimpermeant covalent modifier

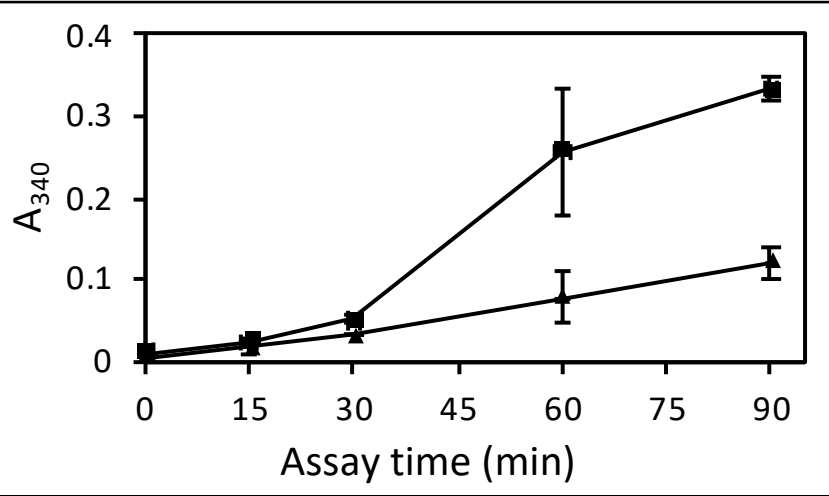

Figure 2: Cell surface GAPDH activity on the presence and absence of DTT. GAPDH assays in the absence $(\mathbf{\Delta})$ and presence $(\boldsymbol{\square})$ of $100 \mu \mathrm{M}$ DTT. 
151 advantage of a membrane-impermeant modifier to deactivate cell-wall associated GAPDH.

152 Attempts to label and extract cell surface GAPDH led to the observation that the biotinylation

153 reagent sulfosuccinimidyl 6-(biotinamido)-hexanoate (Sulfo-NHS-LC biotin) decreased GAPDH

154 activity dramatically, both in cytoplasmic extracts and for the enzyme assayed on the surface of

155 intact cells (Fig. 3). Because Sulfo-NHS-LC biotin is membrane impermeant (44) and will only

156 react with proteins external to the plasma membrane, it can specifically deactivate cell wall

157 GAPDH and leave cytosolic GAPDH unaffected. We treated intact cells with Sulfo-NHS-LC

158 biotin, then washed the cells to remove remaining Sulfo-NHS-LC biotin, resuspended in assay

159 buffer, and assayed for 15-90 min. Unlike the control untreated cells, biotinylated yeast did not

160 have detectable GAPDH activity on their surface for the first 30 minutes (Fig. 3). However,

161 biotinylated yeast showed increasing surface GAPDH between 30 and 90 min (Fig. 3B). This

162 result was consistent with GAPDH being released to the surface from a cellular pool

163 inaccessible to sulfo-NHS-LC biotin, presumably in the cytoplasm. However, the rate of increase

164 of cell surface activity was less than that of the cells not treated with biotinylation reagent.

165 Therefore, about half of the increase shown in Figs. 2 and 3 may be due to secretion of active

166 enzyme to the cell surface during the incubation, but some of the increase may represent more

167 activity of the resident assayable cell surface enzyme, presumably due to the wall

168 permeabilization by DTT. 
covalently modifies primary

171 amines, and consequently may

172 have an effect on all surface

173 proteins and causing secondary

174 effects. Therefore, we
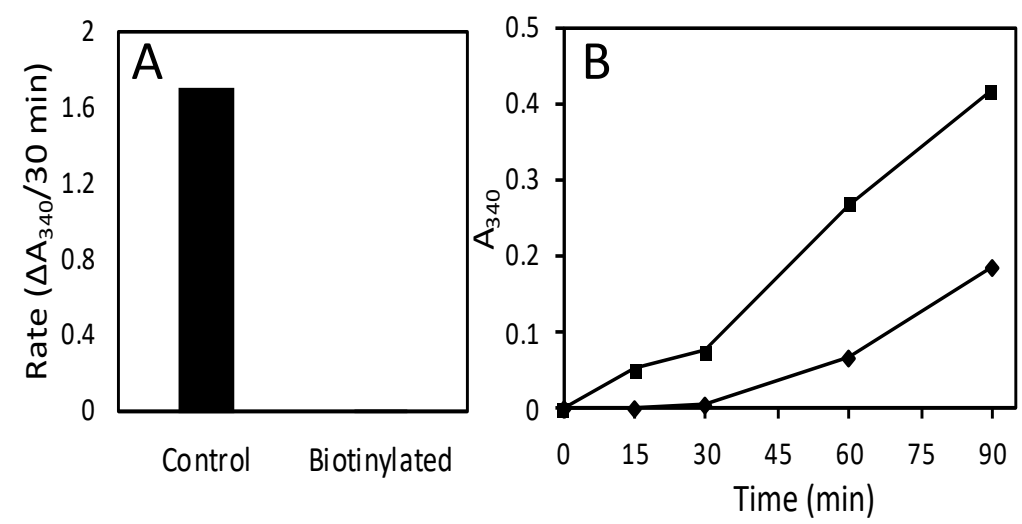

measured invertase activity in

yeast that were either

177 biotinylated or incubated in PBS

178 to see if all surface proteins

179 become dysfunctional upon

180 biotinylation. Invertase activity

181 was unaffected by Sulfo-NHS-

Figure 3. Effect of sulfo-NHS-LC biotin on GAPDH activity. A) Cytosolic Lysate biotinylated with $1 \mathrm{mg} / \mathrm{mL}$ Sulfo-NHS Biotin has low GAPDH activity. Lysate was biotinylated, $10 \mu \mathrm{L}$ of $1: 5$ dilutions of lysate was loaded onto a microtiter plate, $90 \mu \mathrm{L}$ of substrates were added and $A_{340}$ was monitored over 30 minutes. B) Yeast grown to an OD of 0.7 were biotinylated $(\$)$ for $1 \mathrm{hr}$ in PBS pH 7 with $1 \mathrm{mg} / \mathrm{mL}$ sulfo-NHS-LC biotin or PBS $(\boldsymbol{\square})$, and then suspended in TEA buffer containing GAPDH substrates for $15,30,60$ and 90 minutes. $180 \mu \mathrm{L}$ of supernatant was loaded into a microplate and $A_{340}$ was determined. Points are averages of 2 samples.
182

183

184 185

LC biotin (Supplemental Fig. S1). Therefore, biotinylation inactivated GAPDH, but not invertase, consistent with specific modification of GAPDH rather than global perturbation of either wall structure or metabolic activities.

\section{Enzyme assay conditions do not permeabilize the plasma membrane}

In assays of cell wall enzymes, it is important that the plasma membrane is not permeabilized, so that all of the assayed activity derives from extracellular enzyme. We therefore compared PI staining before and after assaying S. cerevisiae for GAPDH surface activity. There was no visible increase in the fraction of propidium iodide positive yeast after assaying yeast for cell wall GAPDH (Fig. 4). Therefore, the increase in GAPDH activity seen after $100 \mu \mathrm{M}$ DTT treatments and recovered after biotinylation was likely due to enzymes externalized by controlled by biological processes and unlikely to be caused by plasma membrane leakage. 


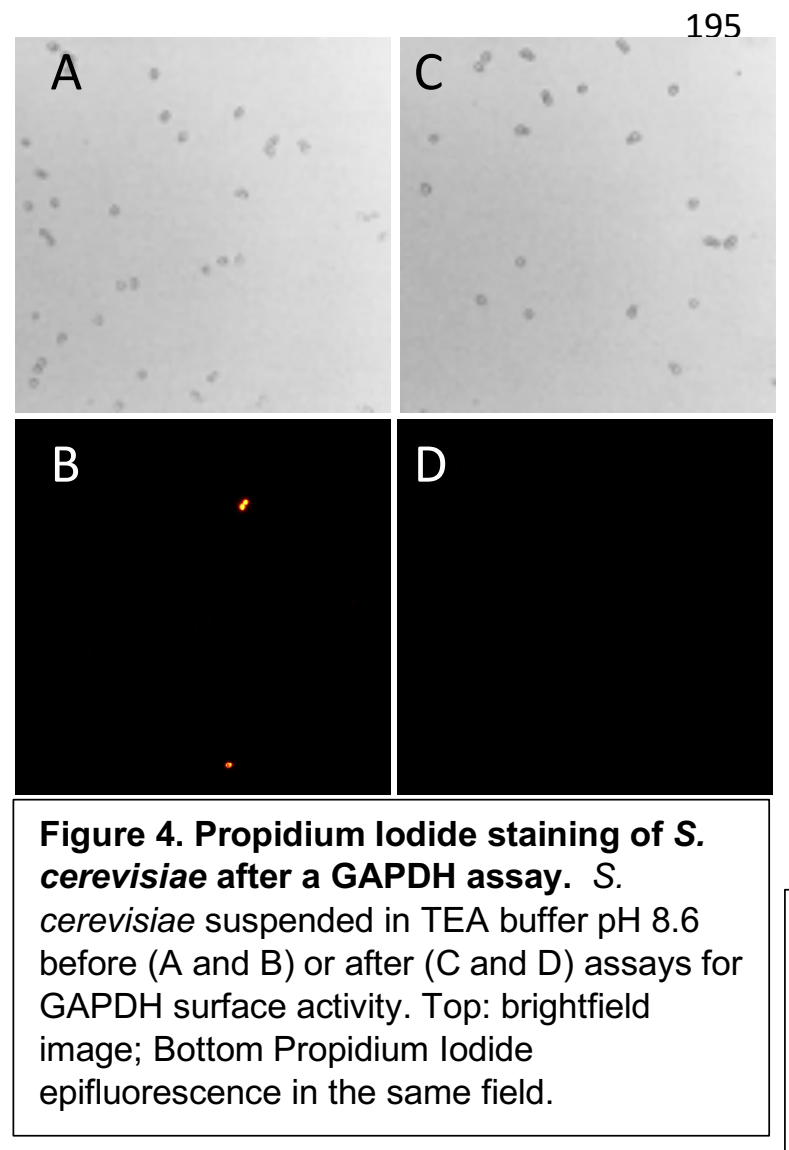
uM DTT for all subsequent assays.
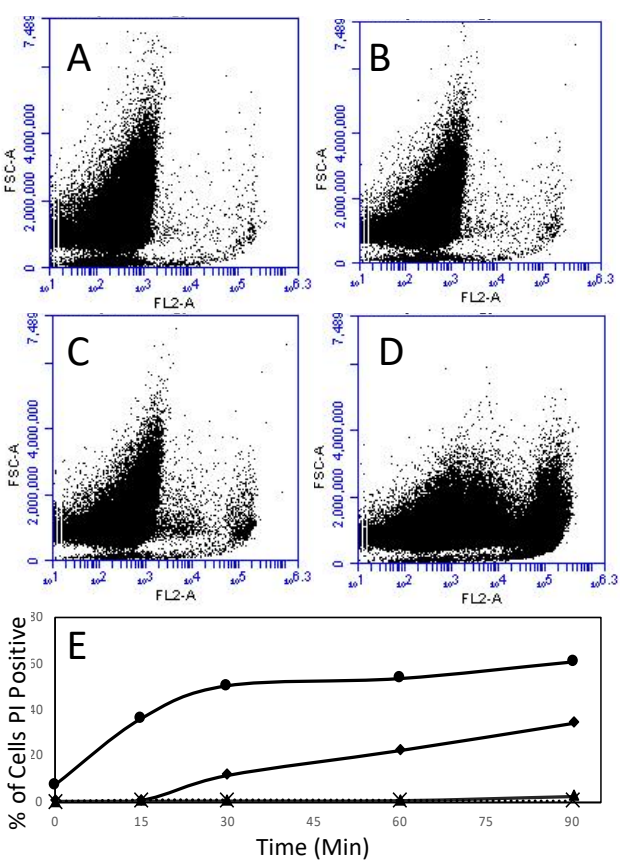

Fig. 5. Flow cytometry of effect of DTT on Propidium lodide staining of $S$. cerevisiae cells. (A-D) Propidium iodide fluorescence after $60 \mathrm{~min}$ incubation at $30 \mathrm{C}$ in TEA buffer $\mathrm{pH}$ 8.6. A) no DTT, B) $100 \mu \mathrm{M}$ DTT, C) $1 \mathrm{mM}$ DTT, D) $10 \mathrm{mM}$ DTT. E) Percentage of cells which were PI positive: DTT concentrations were $(\mathrm{X})$ none, $(\mathbf{\Delta}) 100 \mu \mathrm{M},(\bullet) 1$ $\mathrm{mM},(\bullet) 10 \mathrm{mM}$. membrane (discussed later), so we wanted to ensure DTT concentrations used in whole cell assays for GAPDH on the surface was not permeabilizing the plasma membrane. We incubated S. cerervisiae in a TEA buffer at $\mathrm{pH} 8.6$, at $30 \mathrm{C}$ in different concentrations of DTT and monitored PI fluorescence over time with flow cytometry. The results demonstrated that high concentration of DTT (1 mM or higher) permeabilized the plasma membrane, but $100 \mu \mathrm{M}$ did not cause a significant amount of cells to become PI positive compared to a non-treated control group, and this was consistent over 90 minutes (Fig. 5). Other reducing agents including $\beta$ mercaptoethanol (5-14 mM) or TCEP (5 mM) also increased PI staining of cells, implying permeabilization of the plasma membrane (Supplemental Fig. S2). Therefore, we utilized 100 
209

210

211

212

213

214

215

216

217

218

219

220

221

222

226

227

228

229

230

231

232

233

234

\section{Releasing active cell wall enzymes for in vitro analysis}

We looked at several methods for releasing enzymatically active cell wall proteins from

S. cerevisiae. It was important that the plasma membrane was not permeabilized, so that none

of the activity derived from

cytosolic enzyme. Since $100 \mu \mathrm{M}$

DTT treatment did not

compromise the plasma

membrane, we wanted to know if
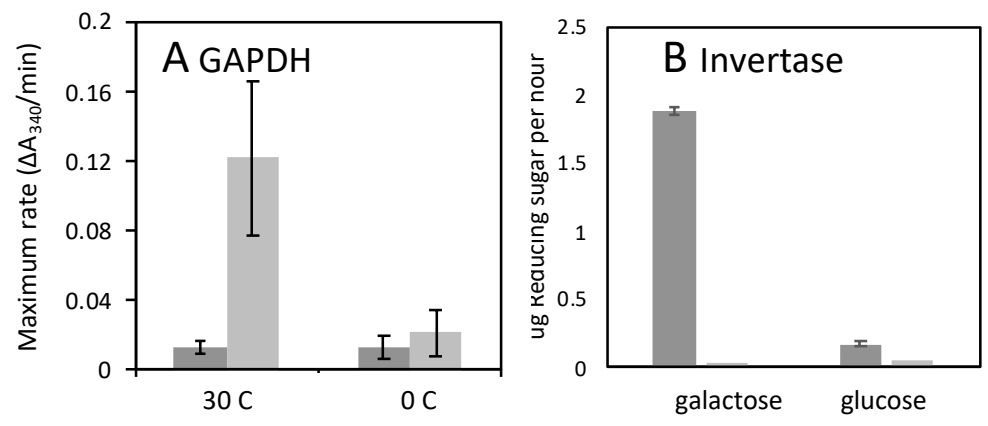

we could use that concentration to

extract cell wall proteins. Cells

were incubated in $100 \mu \mathrm{M}$ DTT for

60 minutes at $30 \mathrm{C}$. When we used

a concentration of $2.5 \times 10^{6}$ cells

Fig. 6. Release of cell wall enzymes from intact cells. Cells were incubated for $1 \mathrm{~h}$ in TEA buffer, then centrifuged and enzymes activities determined. A) GAPDH release after incubation at $30 \mathrm{C}$ or $\mathrm{OC}$ in the absence of DTT (dark grey) or with $100 \mu \mathrm{M}$ DTT present (light grey). B) Invertase activity after growth in galactose or glucose with added sucrose (left, dark grey), or without exogenous substrate (right, light grey).

\section{per $\mathrm{mL}$ (the concentration used}

during in situ cell surface GAPDH assays), there was negligible GAPDH activity released into in the supernatant (not shown). However, at concentrations of $2 \times 10^{8}$ cells per $\mathrm{ml}$ and above, we could monitor supernatant for NADH production. We estimate the GAPDH released by this method is less than $1 \%$ of the total GAPDH present in the wall, based on the level of activity associated with whole cells. This procedure released GAPDH when the cells were incubated at $30 \mathrm{C}$, but not when they were incubated on ice (Fig. 6A). This method also released extracellular invertase from cells grown in galactose, and the yield was similarly about $1 \%$ of the total assayable invertase (Fig. 6B).

To test other published cell wall extraction procedures, we treated cells with $\beta 1,3$ glucanase, mild alkaline treatment, or reducing $(5,6,42,45)$. These methods failed to extract GAPDH without compromising the plasma membrane. Cell wall proteins extracted on ice in 100 mM Tris pH 9.4 supplemented with $2 \%$ sorbitol excludes cytosolic protein such as Cof1 (46). 
235 However, we were unable to detect GAPDH activity in these extracts (data not shown). Treating

236 cells with Zymolyase, a lytic $\beta 1,3$ glucanase, in the presence of $1 \mathrm{M}$ Sorbitol released GAPDH

237 into the medium. However, some cells lysed rapidly, and other cells appreared to be intact but

238 stained with PI. Therefore, neither mild base extraction nor a spheroplast procedure specifically

239 solubilized cell wall GAPDH.

To assess effects of mild base alone, or with increased amounts of reductant, we

suspended S. cerevisiae in $100 \mathrm{mM}$ carbonate buffer containing several different concentrations of $\beta$-mercaptoethanol ( $\beta M E)$, DTT, tris(2-carboxyethyl)phosphine (TCEP), for 2 hours. Cells

were pelleted by centrifugation and supernatants were assayed for GAPDH activity in vitro while

cells were stained with propidium iodide and visualized to monitor plasma membrane leakage.

245 At high concentrations of $\beta$ ME or DTT, GAPDH was released, but a large proportion of yeast

246 treated with these concentrations readily took up propidium iodide (47) (Supplemental Fig. S2).

247 Therefore, incubations in high concentrations of reducing agents probably released cytosolic

248 proteins in addition to cell wall material.

\section{Discussion}

Our results point to several practical approaches to assay of cell wall enzymes in yeast.

252 We have screened assay procedures, and found conditions that facilitate quantitative enzyme

253 assays without compromising the integrity of the plasma membrane. Consequently, we can

254 estimate minimum cell surface concentrations of GAPDH as the amount of active enzyme.

255 Additionally, selective inactivation of GAPDH, coupled with kinetics of recovery of the activity

256 yielded a minimum estimate of the secretion rate. Thus, the results establish criteria for

257 determination of concentrations and secretion rates for fungal cell wall enzymes. 
$A_{340}$ units per hour for $5 \times 10^{5}$ cells. Because the molar extinction coefficient of NADH is 6.2 $\mathrm{X} 10^{3} \mathrm{M}^{-1} \mathrm{~cm}^{-1}$, this corresponds to production of about $3 \times 10^{-10} \mu \mathrm{mol}$ of NADH per cell per minute. Given the specific activity of yeast GAPDH, this amount of activity would result from about $4 \times 10^{4}$ molecules of GAPDH per cell (38). This number is similar to that of other cell surface molecules such as the $S$. cerevisiae sexual agglutinins (48). Note however, that this concentration does not account for any surface GAPDH that is enzymatically inactive. For comparison, invertase, a conventionally secreted highly-expressed surface enzyme is about 100-fold higher in fully de-repressed cells (49). Therefore, cell surface GAPDH concentrations are commensurate with its frequent detection in wall proteomics studies, but are significantly lower than maximal levels of a highly expressed surface enzyme.

Biotinylation as a tool for selectively deactivating GAPDH. Biotinylation is frequently used as a mechanism of tagging cell wall proteins for western blot analysis or proteomics (50), including unconventionally secreted proteins such as enolase (51) and the Hsp70 members Ssa1 and Ssa2 $(52,53)$. To our knowledge, it has not been used to deactivate enzymes in situ. Biotinylation ablated GAPDH activity, but did not alter external invertase activity, so not all external enzymes can be deactivated in this manner. Therefore, labeling intact cells with sulfoNHS-LC biotin did not globally alter classical secretion and s minimally invasive. Sulfo-NHS-LCbiotin contains a charged sulfonate group, making it membrane impermeant (44). Therefore, the reagent specifically deactivated GAPDH that was external to the membrane. Propidium iodide staining and flow cytometry experiments demonstrated that the plasma membrane remained intact as GAPDH activity returned to the surface within 30-60 minutes (Figs. 3-5). Therefore, we conclude that cell surface GAPDH is specifically inactivated by sulfo-NHS-LC-Biotin, and that plasma membrane remains intact both after inactivation, and during extended incubations in assay buffer. 
Sulfo-NHS-LC biotin reacts with

286 primary amines. Based on the structure of

287 yeast Tdh3, which is reported to be the

288 major form of GAPDH in the cell wall with

289 Tdh2 during exponential growth phase (1),

290 we identified lysine residues near the

291 catalytic cysteine, the glyceraldehyde-3-

292 phosphate binding domain, and the NAD

293 binding domain (54). Lysines located near

294 the active site, include LYS160, LYS217 at 5

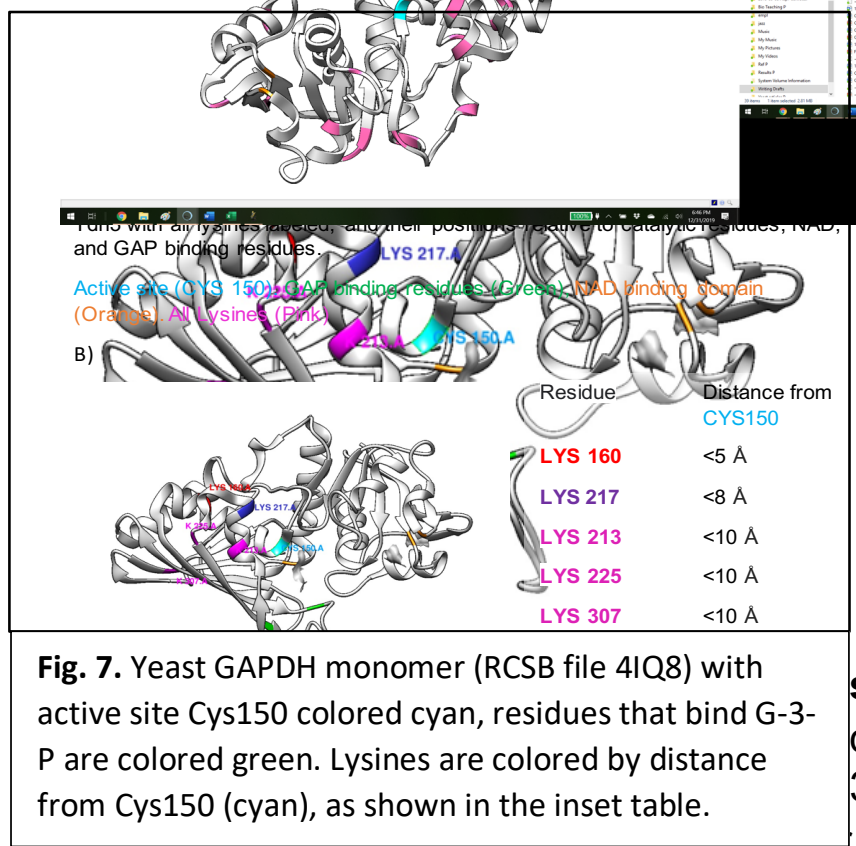

295

and 8 angstroms, as well as LYS 213, 225, 307 within 10 angstroms (Fig. 7). Therefore, it is

likely that Sulfo-NHS-LC is directly inactivating GAPDH by covalently modifying one or more

297 lysines near its active site.

Secretion of GAPDH. After inactivation of surface GAPDH, steady-state levels of activity were re-established in the wall within an hour of incubation at $30^{\circ} \mathrm{C}$ (Fig. 3). Thus, the rate of GAPDH secretion was about $4 \times 10^{4}$ molecules of active enzyme per hour under these conditions. The recovery was dependent on incubation temperature, implying that the recovery was due to a secretory event rather than passive leakage from the cytosol though damaged membranes.

Reducing agents can compromise the plasma membrane. One striking observation we made is that $\mathrm{mM}$ concentrations of reducing agents used to extract cell wall proteins $(5,30$, $55,56)$ can compromise the plasma membrane, leading to propidium iodide uptake. This is consistent with observations of Curvin et al, which used cofilin as a marker for cytosolic leakage (46). 
To extract cell wall proteins for enzymology while avoiding cytosolic contamination, we recommend incubating S. cerevisiae in $100 \mu \mathrm{M}$ DTT as described above and monitoring yeast

311 for cytosolic permeability with propidium iodide. GAPDH and invertase are considered

312 periplasmic (held in place between the wall and the plasma membrane) $(1,57,58)$, so this

313 technique can extract proteins associated with the innermost layer of the cell wall. We also

314 recommend passing supernatant through a $.22 \mu \mathrm{m}$ filter to avoid contaminating extracts with

315 unpelleted cells. Unfortunately, extraction with 100 uM DTT is inefficient, based on the observation that about $1 \%$ of the activity of GAPDH or invertase is released into the medium.

Thus, there are techniques for assay of cell wall enzymes in situ. A minimum estimate is secretion rates, and it can be readily extracted from the wall without cytosolic contamination.

\section{Methods}


centrifuging at full speed $(13,000 \times \mathrm{G})$ for 1 minute. $180 \mu \mathrm{L}$ of the supernatant was collected and A340 was measured on a Biotek Synergy 2 plate reader. $180 \mu \mathrm{L}$ of supernatant from a negative control reaction of $5 \times 10^{\wedge} 5$ cells without glyceraldehyde-3-phosphate or without cells were used as a blank. To determine kinetics of NADH production, cells were incubated for 0120 minutes before analysis of supernatants.

To determine how incubation in DTT alters GAPDH activity on the surface over time, $500 \mathrm{~K}$ yeast cells in $20 \mu \mathrm{L}$ of TBS were mixed with in $160 \mu \mathrm{L}$ of TEA buffer with or without DTT (100 uM) and incubated for the times stated. After incubation, NAD and glyceraldehyde-3phosphate were added, and $2 \mu \mathrm{L}$ of $10 \mathrm{mM}$ of DTT was added to reactions lacking DTT. The tubes were incubated at $30 \mathrm{C}$ for 30 minutes, the supernatant was collected and analyzed for $\mathrm{NADH}$ production by reading an $\mathrm{A} 340$.

\section{Extraction of cytoplasmic GAPDH}

S. cerevisiae were lysed with glass beads in PBS, with a 1:1000 dilution of yeast protease inhibitor cocktail set IV (Calbiochem), the lysate was cleared by centrifugation at 4C at full speed on a microcentrifuge, and supernatant was analyzed for GAPDH activity.

\section{In vitro GAPDH kinetics}

$10 \mu \mathrm{L}$ of either a cell wall extract, whole cell lysate, or 10 -fold dilutions were loaded into a microplate. A Biotek synergy 2 plate reader was prewarmed to $30 \mathrm{C}, 90 \mu \mathrm{L}$ of TEA buffer containing $1 \mathrm{mM} \mathrm{NAD+,} \mathrm{glyceraldehyde} 3$ phosphate, and $100 \mu \mathrm{M}$ DTT was added and an OD340 was monitored over 60 minutes. Negative control wells contained $10 \mu \mathrm{L}$ of the buffer used to extract protein mixed with the other reagents, or extract was mixed with TEA buffer containing all of the reagents except for glyceraldehyde-3-phosphate. To calculate GAPDH 
activity, we determined the slope of the steepest linear part of the OD340 curve during the first 5-60 minutes.

\section{Biotinylation of GAPDH}

Cytosolic lysate was covalently modified with or without $1 \mathrm{mg} / \mathrm{mL}$ sulfo-NHS-LC biotin (ApexBio) for 1 hour. The biotinylated and non-biotinylated lysates were then washed in a 10kDa membrane cutoff filter (Sigma) with PBS, $10 \mu \mathrm{L}$ was loaded into a microplate with $90 \mu \mathrm{L}$ substrates and analyzed for GAPDH activity.

To biotinylate intact yeast, S. cerevisiae were washed and resuspended at an $\mathrm{OD}_{600 \mathrm{~nm}}=2.5$ to 5 in PBS, with or without $1 \mathrm{mg} / \mathrm{mL}$ Sulfo-NHS-LC biotin for 1 hour at $4 \mathrm{C}$ or on ice. The treated cells were washed twice and resuspended in TBS to measure GAPDH activity as above, or in citrate buffer to measure invertase.

\section{Whole cell Invertase assays}

S. cerevisiae BY4741 and BY4743 were grown to an $\mathrm{OD}_{600}$ of $0.45-0.55$ in Yeast Extract-Peptone medium with $2 \%$ galactose as carbon sourse (YPGal), concentrated to an $\mathrm{OD}_{600 \mathrm{~nm}}=1 \mathrm{in} 20 \mathrm{mM}$ sodium citrate buffer $(\mathrm{pH} 5) .150 \mu \mathrm{L}$ of this cell suspension was mixed with $50 \mu \mathrm{L}$ of $0.4 \mathrm{M}$ sucrose to a final concentration of $\mathrm{OD}_{600 \mathrm{~nm}}=0.75$ and $0.1 \mathrm{M}$ sucrose, and incubated at $30 \mathrm{C}$. After $1 / 2$ hour suspensions were pelleted and reducing sugar released was quantified by boiling 1:1000 dilution in tetrazolium blue (Sigma) and boiled for 3 minutes, and an $\mathrm{OD}_{670}$ measured in either a Spectronic 600 or Biotek Synergy plate reader. The $\mathrm{OD}_{670}$ was used to quantify reducing sugar against a set of glucose standards (59). All assays presented were carried out in duplicate, and are representative of 3 or more independent experiments.

To measure invertase extracted from cell walls, $S$. cerevisiae was grown to an $\mathrm{OD}_{600 \mathrm{~nm}}$ of 0.5 in YPD (to suppress invertase) or YPGal (to derepress invertase expression), and resuspended to an of $\mathrm{OD}_{600 \mathrm{~nm}}=20$, and 23 , respectively, in TEA buffer $(40 \mathrm{mM}$ 
384

385

386

387

388

389

390

391

392

393

394

395

396

397

398

399

400

401

402

403

404

405

406

407

408

triethanolamine, Sigma, 50 mM Na2HPO4, 7.5 mM EDTA, pH 8.6) containing $100 \mu$ M DTT

for 60 minutes at $30 \mathrm{C} .150 \mu \mathrm{L}$ of $1000 \times \mathrm{g}$ supernatant was collected and mixed with 50

$\mu \mathrm{L}$ of sucrose in citrate buffer as stated above, except reactions were run for 60 minutes

and the reaction was terminated by immediately diluting in tetrazolium blue, which is

prepared in $\mathrm{NaOH}$ and will denature enzyme. Micrograms of reducing sugar released by invertase was measured as an $A_{670 n m}$ and compared to a glucose curve (59).

\section{Propidium iodide staining}

S. cerevisiae were treated as stated, stained with either 2 to $20 \mathrm{ug} / \mathrm{mL}$ of propidium iodide $(\mathrm{PI})$

(Sigma), concentrations within ranges reported for live/dead staining $(4,60,61)$ and visualized under fluorescence microscopy using a TRITC filter.

\section{Flow cytometry}

We incubated BY4743 at at a concentration of $2.5 \times 10^{\wedge} 5$ per $\mathrm{mL}$ in TEA buffer (pH 8.6) with 0$10 \mathrm{mM}$ DTT at 30C for 0-90 minutes, and at each timepoint, removed $100 \mathrm{uL}$, added PI to a final concentration of $2 \mathrm{ug} / \mathrm{mL}$, incubated for an additional 5 minutes to ensure all dead cells take up the dye (61), and measured PI fluorescence on a BD Accuri flow cytometer.

\section{Cell wall extraction procedures}

To generate spheroplasts, S. cerevisiae strain BY4743 was resuspended in PBS with or without $1 \mathrm{M}$ sorbitol. 1 unit of Zymolyase (Zymogen) was added to the mixture and lysis was monitored visually in the tube lacking sorbitol. Spheroplasted yeasts were identified using phase contrast microscopy at 400X magnification. The spheroplasts stabilized in sorbitol were pelleted at 2000 RPM, and supernatant was collected and assayed for enzyme activity in vitro. The spheroplasts were washed in PBS $+1 \mathrm{M}$ sorbitol, stained with PI as above (the volume of PI added did not exceed $1 \%$ of the total volume). Reducing agents for GAPDH release and cell viability were 
409 added to $2 \times 10^{6}$ cells $/ \mathrm{mL}$ in $100 \mathrm{mM}$ carbonate buffer containing the indicated concentrations of

410 reducing agents at $30 \mathrm{C}$ for 2 hours. An aliquot of cells was stained with $\mathrm{PI}$ as above, remaining

411 cells were pelleted and $10 \mu \mathrm{L}$ of serial dilutions were used to measure GAPDH activity in the

412 supernatant.

413 To extract cell wall proteins using $100 \mu \mathrm{M}$ DTT, S. cerevisiae were washed $2 \mathrm{X}$ in TEA

414 buffer and concentrated to an $\mathrm{OD}_{600}=10-30$. DTT was added to a final concentration of $100 \mu \mathrm{M}$

415 from a $100 \mathrm{mM}$ frozen stock solution, the cells were incubated on either ice or at $30 \mathrm{C}$ for 60

416 minutes and then pelleted. $90 \%$ of the Supernatant was collected to avoid disturbing the pellet.

417 In later experiments the supernatant was passed through a .22um Durapore filter (Sigma) to

418 remove any remaining cells. 


\section{Literature Cited}

1. Delgado ML, Connor EO, Azorın I, Renau-piqueras J, Gil ML, Gozalbo D. 2001. The glyceraldehyde-3-phosphate dehydrogenase polypeptides encoded by the Saccharomyces cerevisiae TDH1, TDH2 and TDH3 genes are also cell wall proteins. Microbiology 147:411-417.

2. Delgado L, Gil L, Gozalbo D. 2003. Starvation and temperature upshift cause an increase in the enzymatically active cell wall-associated glyceraldehyde-3-phosphate dehydrogenase protein in yeast. FEMS Yeast Res 4:297-303.

3. Giardina BJ, Chiang HL. 2013. Fructose-1,6-bisphosphatase, malate dehydrogenase, isocitrate lyase, phosphoenolpyruvate carboxykinase, glyceraldehyde-3-phosphate dehydrogenase, and cyclophilin a are secreted in Saccharomyces cerevisiae grown in low glucose. Commun Integr Biol 6.

4. Braconi D, Amato L, Bernardini G, Arena S, Orlandini M, Scaloni A, Santucci A. 2011. Surfome analysis of a wild-type wine Saccharomyces cerevisiae strain. Food Microbiol 28:1220-1230.

5. Chaffin WL. 2008. Candida albicans cell wall proteins. Microbiol Mol Biol Rev 72:495544.

6. Gil-bona A, Amador-garcía A, Gil C, Monteoliva L. 2018. The external face of Candida albicans: A proteomic view of the cell surface and the extracellular environment. $\mathrm{J}$ Proteomics 180:70-79.

7. Gil-Navarro I, Gil ML, Casanova M, O'Connor J, Martinez JP, Gozalbo D. 1997. The glycolytic enzyme glyceraldehyde-3-phosphate dehydrogenase of Candida albicans is a surface antigen. J Bacteriol 179:4992-4999.

8. Barbosa MS, Báo SN, Ferrari P, Faria FP De, Felipe MSS, Feitosa S, Soares MJ, Maria C, Soares DA, Jose M, Mendes-giannini S. 2006. Glyceraldehyde-3-Phosphate Dehydrogenase of Paracoccidioides brasiliensis Is a Cell Surface Protein Involved in Fungal Adhesion to Extracellular Matrix Proteins and Interaction with Cells. Infect Immun 74:382-389.

9. Chauhan AS, Kumar M, Chaudhary S, Patidar A, Dhiman A, Sheokand N, Malhotra H, Raje Cl, Raje M. 2017. Moonlighting glycolytic protein glyceraldehyde-3-phosphate dehydrogenase ( GAPDH ): an evolutionarily conserved plasminogen receptor on mammalian cells. FASEB J 2638-2648.

10. Sheokand N, Kumar S, Malhotra H, Tillu V, Raje Cl, Raje M. 2013. Secreted glyceraldehye-3-phosphate dehydrogenase is a multifunctional autocrine transferrin receptor for cellular iron acquisition. Biochim Biophys Acta - Gen Subj 1830:3816-3827.

11. Griffiths J, Shaw S. 1977. Glyceraldehyde phosphate dehydrogenase (total and isoenzyme activity) in the early diagnosis of myocardial infarction. Clin Chem 23:245249.

12. Ringel AE, Ryznar R, Picariello H, Huang K, Lazarus AG, Holmes SG. 2013. Yeast Tdh3 ( Glyceraldehyde 3-Phosphate Dehydrogenase ) Is a Sir2-Interacting Factor That Regulates Transcriptional Silencing and rDNA Recombination. PLoS Genet 9:e1003871.

13. Tisdale EJ, Kelly C, Artalejo CR. 2004. Glyceraldehyde-3-phosphate Dehydrogenase Interacts with Rab2 and Plays an Essential Role in Endoplasmic Reticulum to Golgi Transport Exclusive of Its Glycolytic Activity *. J Biol Chem 279:54046-54052. 
14. Gozalbo D, Gil-Navarro I, Azorín I, Renau-Piqueras J, Martínez JP, Gil ML. 1998. The cell wall-associated glyceraldehyde-3-phosphate dehydrogenase of Candida albicans is also a fibronectin and laminin binding protein. Infect Immun 66:2052-9.

15. Branco P, Francisco D, Chambon C, Hébraud M, Arneborg N, Almeida MG, Caldeira J, Albergaria H. 2014. Identification of novel GAPDH-derived antimicrobial peptides secreted by Saccharomyces cerevisiae and involved in wine microbial interactions. Appl Microbiol Biotechnol 98:843-853.

16. Branco P, Kemsawasd V, Santos L, Caldeira J, Almeida MG, Arneborg N, Albergaria H, Moniz E, Universit C, Granja Q, Caparica M. 2017. Saccharomyces cerevisiae accumulates GAPDH-derived peptides on its cell surface that induce death of nonSaccharomyces yeasts by cell-to-cell contact. FEMS Microbiol Ecol 1-10.

17. Satala D, Karkowska-Kuleta J, Zelazna A, Rapala-Kozik M, Kozik A. 2020. Moonlighting proteins at the candidal cell surface. Microorganisms 8:1-25.

18. Karkowska-Kuleta J, Satala D, Bochenska O, Rapala-Kozik M, Kozik A. 2019. Moonlighting proteins are variably exposed at the cell surfaces of Candida glabrata, Candida parapsilosis and Candida tropicalis under certain growth conditions. BMC Microbiol 19:1-13.

19. Perumal P, Gutierrez D, Xim P. 2012. Cell surface shaving of Candida albicans biofilms , hyphae, and yeast form cells. Proteomics 12:2331-2339.

20. Cohen MJ, Chirico WJ, Lipke PN. 2020. Through the back door: Unconventional protein secretion. Cell Surf https://doi.org/10.1016/j.tcsw.2020.100045.

21. Tanaka T, Kondo A. 2015. Cell-surface display of enzymes by the yeast Saccharomyces cerevisiae for synthetic biology. FEMS Yeast Res 15:1-9.

22. Kambe-Honjoh H, Ohsumi K, Shimoi H, Nakajima H, Kitamoto K. 2000. Molecular breeding of yeast with higher metal-adsorption capacity by expression of histidine-repeat insertion in the protein anchored to the cell wall. J Gen Appl Microbiol 46:113-117.

23. Younger D, Berger S, Baker D, Klavins E. 2017. High-throughput characterization of protein-protein interactions by reprogramming yeast mating. Proc Natl Acad Sci U S A 114:12166-12171.

24. Gonzalez M, Lipke PN, Ovalle R. 2009. Chapter 15 GPI Proteins in biogenesis and structure of yeast cell walls. Enzym, 1st ed. 26:321-356.

25. Ecker M, Deutzmann R, Lehle L, Mrsa V, Tanner W. 2006. Pir proteins of Saccharomyces cerevisiae are attached to $\beta-1,3-$ glucan by a new protein-carbohydrate linkage. J Biol Chem 281:11523-11529.

26. Dranginis AM, Rauceo JM, Coronado JE, Lipke PN. 2007. A biochemical guide to yeast adhesins: glycoproteins for social and antisocial occasions. Microbiol Mol Biol Rev 71:282-294.

27. Nombela C, Gil C, Chaffin WL. 2006. Non-conventional protein secretion in yeast. Trends Microbiol 14:15-21.

28. Novick P, Ferro S, Schekman R. 1981. Order of Events in the Yeast Secretory Pathway. Cell 25:461-469.

29. Novick P, Schekman R. 1979. Secretion and cell-surface growth are blocked in a temperature-sensitive mutant of Saccharomyces cerevisiae. Proc Natl Acad Sci U S A 
76:1858-1862.

30. Cleves AE, Cooper DN, Barondes SH, Kelly RB, Francisco S. 1996. A new pathway for protein export in Saccharomyces cerevisiae. J Cell Biol 133:1017-26.

31. Hughes RC. 1999. Secretion of the galectin family of mammalian carbohydrate-binding proteins. Biochim Biophys Acta - Gen Subj 1473:172-185.

32. Duran JM, Anjard C, Stefan C, Loomis WF, Malhotra V. 2010. Unconventional secretion of Acb1 is mediated by autophagosomes. J Cell Biol 188:527-536.

33. Lee J, Ye Y. 2018. The Roles of Endo-Lysosomes in Unconventional Protein Secretion. Cells 7:198.

34. Reindl M, Hänsch S, Weidtkamp-peters S, Schipper K. 2019. A Potential Lock-Type Mechanism for Unconventional Secretion in Fungi. Int J Mol Sci 20:1-13.

35. Mencher A, Morales P, Valero E, Tronchoni J, Patil KR, Gonzalez R. 2020. Proteomic characterization of extracellular vesicles produced by several wine yeast species. Microb Biotechnol 13:1581-1596.

36. Oliveira DL, Nakayasu ES, Joffe LS, Guimar??es AJ, Sobreira TJP, Nosanchuk JD, Cordero RJB, Frases S, Casadevall A, Almeida IC, Nimrichter L, Rodrigues ML. 2010. Characterization of yeast extracellular vesicles: Evidence for the participation of different pathways of cellular traffic in vesicle biogenesis. PLoS One 5:e11113.

37. Vargas G, Rocha JDB, Oliveira DL, Albuquerque PC, Frases S, Santos SS, Nosanchuk JD, Gomes AMO, Medeiros LC a S, Miranda K, Sobreira TJP, Nakayasu ES, Arigi E a., Casadevall A, Guimaraes AJ, Rodrigues ML, Freire-de-Lima CG, Almeida IC, Nimrichter L. 2015. Compositional and immunobiological analyses of extracellular vesicles released by Candida albicans. Cell Microbiol 17:389-407.

38. Linck A, Vu X, Essl C, Hiesl C, Boles E, Oreb M. 2014. On the role of GAPDH isoenzymes during pentose fermentation in engineered Saccharomyces cerevisiae. FEMS Yeast Res 14:389-398.

39. Cyrne L, Antunes F, Sousa-Lopes A, Diaz-Bérrio J, Marinho S. 2010. Glyceraldehyde-3phosphate dehydrogenase is largely unresponsive to low regulatory levels of hydrogen peroxide in Saccharomyces cerevisiae. BMC Biochem 11:49.

40. Klis FM, Priem J, Munnik T. 1990. The Glucanase-Soluble Mannoproteins Limit Cell Wall Porosity in Saccharomyces cerevisiae. yeast 6:491-499.

41. Sommer A, Lewis MJ. 1971. Effect of Dithiothreitol on Yeast: Sphaeroplast Formation and Invertase Release. J Gen Microbiol 68:327-335.

42. Casanova M, Chaffin WL. 1991. Cell wall glycoproteins of Candida albicans as released by different methods. J Gen Microbiol 137:1045-1051.

43. Ponton J, Jones JM. 1986. Analysis of cell wall extracts of Candida albicans by sodium dodecyl sulfate-polyacrylamide gel electrophoresis and Western blot techniques. Infect Immun 53:565-572.

44. Stegmayer C, Kehlenbach A, Tournaviti S, Wegehingel S, Zehe C, Denny P, Smith DF, Schwappach B, Nickel W. 2005. Direct transport across the plasma membrane of mammalian cells of Leishmania HASPB as revealed by a $\mathrm{CHO}$ export mutant. J Cell Sci 118:517-527. 
45. Wilcox CA, Fuller RS. 1991. Posttranslational processing of the prohormone-cleaving Kex2 protease in the Saccharomyces cerevisiae secretory pathway. J Cell Biol 115:297307.

46. Curwin A, Brouwers N, Adell MAY, Teis D, Turacchio G, Parashuraman S, Ronchi P, Malhotra V. 2016. ESCRT-III drives the final stages of CUPS maturation for unconventional protein secretion. Elife 1-25.

47. Klis F, de Jong M, Brul S, W. J. de Groot P. 2007. Extraction of cell surface-associated proteins from living yeast cells. Yeast 24:253-258.

48. Lipke PN, Wojciechowicz D, Kurjan J. 1989. AG alpha 1 is the structural gene for the Saccharomyces cerevisiae alpha-agglutinin, a cell surface glycoprotein involved in cellcell interactions during mating. Mol Cell Biol 9:3155-3165.

49. Baseer A, Shall S. 1971. Properties of the internal invertase of yeast, Saccharomyces cerevisiae. Biochem Biophys Acta (BBA)-Enzymology 250:192-202.

50. Casanova M, Lopez-Ribot JL, Martinez JP, Sentandreu R. 1992. Characterization of cell wall proteins from yeast and mycelial cells of Candida albicans by labelling with biotin: Comparison with other techniques. Infect Immun 60:4898-4906.

51. Edwards SR, Braley R, Chaffin WL. 1999. Enolase is present in the cell wall of Saccharomyces cerevisiae. FEMS Microbiol Lett 177:211-216.

52. Lopez-Ribot JL, Chaffin WLAJ, Lo L, Chaffin WLAJ. 1996. Members of the Hsp70 family of proteins in the cell wall of Saccharomyces cerevisiae. J Bacteriol 178:4724-4726.

53. López-Ribot JL, Alloush HM, Masten BJ, Chaffin WL. 1996. Evidence for presence in the cell wall of Candida albicans of a protein related to the hsp70 family. Infect Immun 64:3333-3340.

54. Liu Q, Wang H, Liu H, Teng M, Li X. 2012. Preliminary crystallographic analysis of glyceraldehyde-3-phosphate dehydrogenase 3 from Saccharomyces cerevisiae. Acta Crystallogr F68:978-980.

55. Lu CF, Kurjan J, Lipke PN. 1994. A pathway for cell wall anchorage of Saccharomyces cerevisiae alpha-agglutinin. Mol Cell Biol 14:4825-4833.

56. Giardina BJ, Stanley BA, Chiang H. 2014. Glucose induces rapid changes in the secretome of Saccharomyces cerevisiae. Proteome Sci 12:1-21.

57. Lipke PN, Ovalle R. 1998. Cell Wall Architecture in Yeast: New Structure and New Challenges. J Bacteriol 180:3735-3740.

58. Tanino T, Matsumoto T, Fukuda H, Kondo A. 2004. Construction of system for localization of target protein in yeast periplasm using invertase. J Mol Catal 28:259-264.

59. Jue CK, Lipke PN. 1985. Determination of reducing sugars in the nanomole range with tetrazolium blue. J Biochem Biophys Methods 11:109-115.

60. Kwolek-Mirek M, Zadrag-Tecza R. 2014. Comparison of methods used for assessing the viability and vitality of yeast cells. FEMS Yeast Res 14:1068-1079.

61. Atanasova M, Yordanova G, Nenkova R, Ivanov Y, Godjevargova T, Dinev D. 2019. Brewing yeast viability measured using a novel fluorescent dye and image cytometer. Biotechnol Biotechnol Equip 33:548-558. 
bioRxiv preprint doi: https://doi.org/10.1101/2020.10.12.336925; this version posted October 13,2020 . The copyright holder for this preprint (which was not certified by peer review) is the author/funder, who has granted bioRxiv a license to display the preprint in perpetuity. It is made available under aCC-BY-NC-ND 4.0 International license.

590

591 
$595{ }^{1}$ Biology Department, Brooklyn College of the City University of New York, Brooklyn, 596 New York, 11210 USA

5972 The Graduate Center of the City University of New York, New York, New York, 10016 598 USA

\section{Cell surface invertase activity of biotinylated cells}

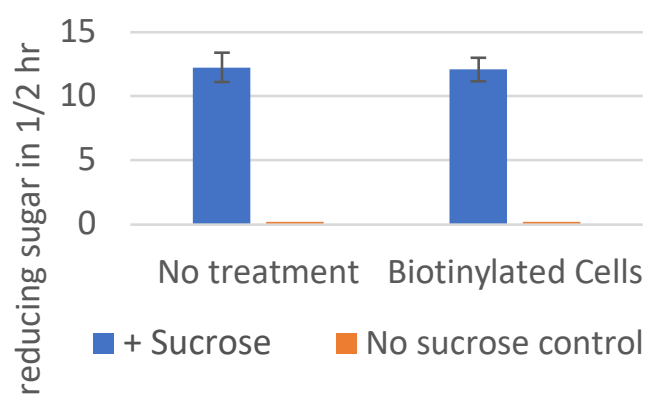

Supplemental Fig. S1. Invertase activity of intact cells with and without treatment with Sulfo-NHS-LC biotin. Yeast were grown in YPGal medium, washed, treated or not with sulfo-NHS-LC biotin, then incubated with or without sucrose, and reducing sugar 
A)

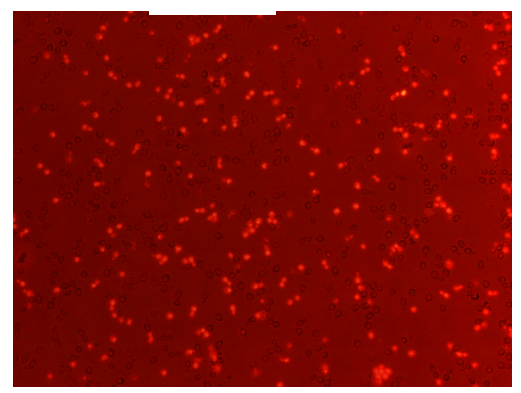

B) $140 \mathrm{mM} \beta \mathrm{ME}(1 \%)$

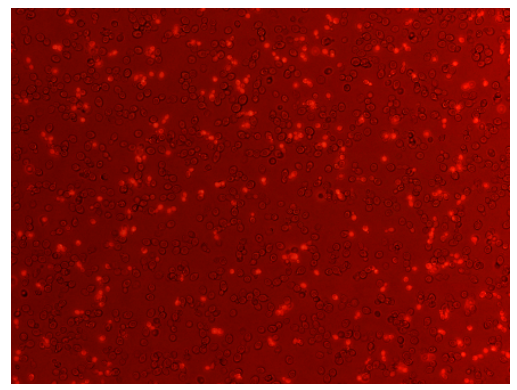

E) $20 \mathrm{mM}$ DTT

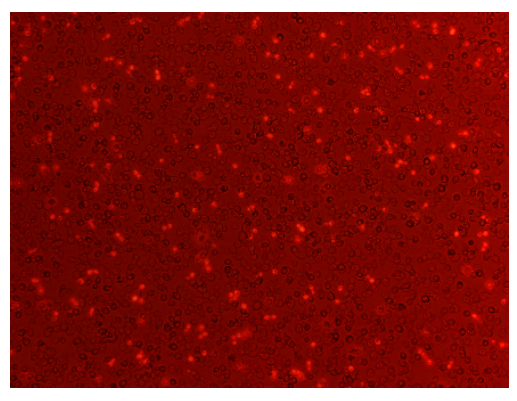

C) $20 \mathrm{mM} \beta M E$

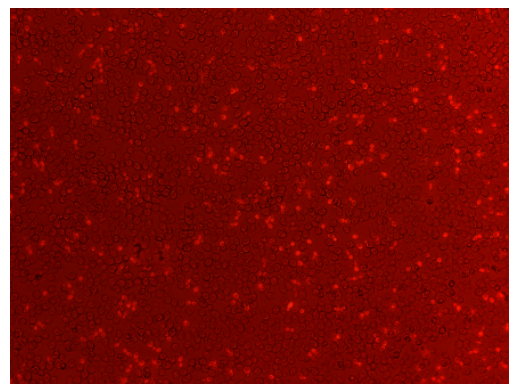

F) $5 \mathrm{mM} \mathrm{DTT}$

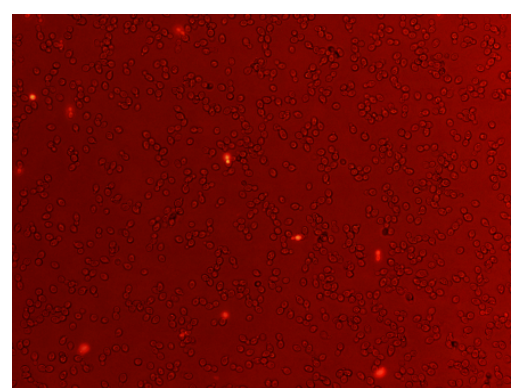

D) $5 \mathrm{mM} \beta \mathrm{ME}$

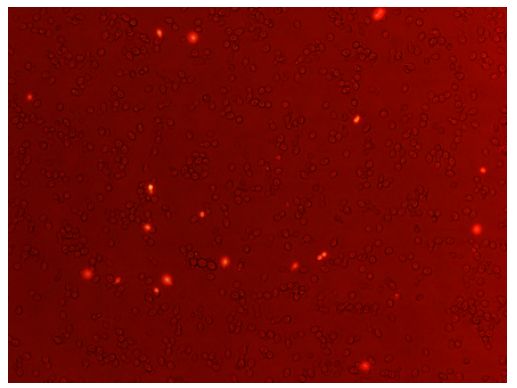

G) $5 \mathrm{mM}$ TCEP

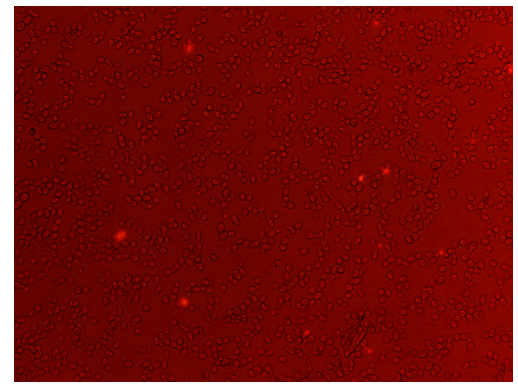

H) No reducing agent

Supplemental Fig. S2. Exposing yeast to reducing agents can release cell wall enzymes, but also permeabilizes cells. A) GAPDH activity in supernatant from BY4743 S. cerevisiae after incubating in various reducing agents for 120 minutes. B-G) Yeast incubated in reducing agents after 2 hrs have compromised plasma membranes PI fluorescent (bright red) yeast combined with a brightfield microscopy to visualize total amount of yeast (dark spots) after exposing yeast to reducing agents compared to yeast in carbonate buffer only $\mathbf{( H )}$. Values in A are single technical replicates and representative of 2 experiments. 